Australian Journal of

Educational Technology

\title{
Malaysian students face the age of information technology
}

\author{
Nancy Hunt and Alison Kuiper \\ Lincoln University \\ Canterbury, New Zealand
}

\begin{abstract}
Malaysia is a developing country with a fully articulated vision of itself being a country which is fully developed economically, politically, socially and spiritually by the year 2020. A dominant feature of national policy is the emphasis placed on information technology while remaining a moral and ethical society. It is within this societal context that Malaysian students learn about information technology and experience the Internet. As indicated by the findings of this research, Malaysian students share some of the same complaints students in fully developed countries express - too few campus connections, server breakdowns, and inadequate bandwidth for multimedia data transmission. Their favourite activities - making new friends and exploring romantic relationships - are typical adolescent behaviour across cultures. However, their oft stated concerns about user addiction and the availability of pornographic material is perhaps unique to this group of young adults.
\end{abstract}

Malaysia is a developing country which is advantageously placed in Asia as a gateway to other parts of the world and with geographic, cultural and linguistic links to many nations. It is politically stable but with low wage rates so that it attracts investment from other Asian countries. Malaysia has industrialised rapidly so that manufactured goods have replaced commodities as the major export earner. It is still a developing rather than a developed country but the Prime Minister, Datuk Seri Dr Mahathir Mohamad, has articulated a strong vision of the nation in the year 2020 as a country which is developed economically, politically, socially and spiritually (Ahmad Sarji Abdul Hamid, 1996).

A dominant feature of national policy promoting this development is the emphasis placed by the government on information technology. Dr Mahathir foresees Malaysia being "a pioneer in electronic government, a multimedia-networked paperless administration when the Multimedia Super Corridor [MSC] becomes a reality by the year 2000" ("A Global Facilitator", 1996, p.2). The MSC is to be a massive $15 \times 50 \mathrm{~km}$ square area spreading south from the Kuala Lumpur city centre to the new 
International Airport at Sepang. It will include Putra Jaya, the new hightech administrative capital, and IT City, an urban development of smart buildings with the latest information infrastructure. The entire area will be serviced by a fibre optics network that will directly link the MSC with ASEAN, Japan, the US, and Europe.

The vision is far more than a business development; the MSC is envisaged as "the leading edge of a new national strategy for Malaysia to achieve the goals described in our country's vision 2020" (Matathir, 1996a, paragraph 29). These goals include not just economic development but development along political, social, spiritual, psychological and cultural dimensions. It is a unique vision with Malaysia aiming to be not like any of the 19 "developed countries" but "a developed country in our own mould" (Matathir, 1996b, paragraph 4). Central to this goal is the fifth of the nine challenges identified as crucial to the achievement of the vision: the establishment of a moral and ethical society.

It is within this societal context that Malaysian students learn about information technology and experience the Internet. This paper tells the story of one such group of Malaysian students.

\section{Instructional setting}

The subjects of this study were students in a first year university course in business communication offered in Malaysia through a joint New Zealand-Malaysia institutional venture. In their first semester the students take three subjects: Computing and Business Communication (both taught by lecturers from New Zealand), and Malaysian History and Culture (taught by Malaysian faculty). Degrees are awarded by the New Zealand University.

Some of the students are staff members of the employing company who have been given the opportunity to study for a bachelor's degree in commerce, others are scholarship students working towards a qualification in accounting. The students come from all over Malaysia but are resident during the teaching semester.

\section{Class activities related to information technology}

Much of the instruction in the early part of the business communications subject focused on models of communication and the development of students' speaking and writing skills. Students were required to write a research essay entitled "The achievement of Malaysia's Vision 2020 relies on the widespread access to communication technology". These essays revealed that the students were unanimous in their support of Vision 2020 and in the belief that information technology was crucial to its achievement. Like the Prime Minister, they envisaged benefits and progress from widespread access to information technology. Their bibliographies showed they had made use of published library resources, 
newspapers (particularly The New Straits Times which has extensive coverage of governmental initiatives and IT issues) and, in some cases, information gleaned from the Internet.

One of the lectures presented later in the semester dealt specifically with the use of information technology to support business communication. The three primary topics addressed were: a) an overview of the Internet and World Wide Web; b) business uses for the Web, particularly those related to marketing a company and product; and c) the potential impact the proliferation of the Web will have on society and the way we conduct business.

The lecture was delivered using a quantity of black/white and colour PowerPoint-produced slides which highlighted the points being discussed through textual outlines, graphic illustrations, and exemplifying Web pages from major corporations such as Cadbury Limited [www.cadbury.co.uk], Sony Electronics [www.sel.sony.com], and Adobe Software [www.adobe.com/supportservice/main.html].

It was obvious from the students' body language and their responses to intermittent questions regarding their experiences with the Internet and the World Wide Web that they were highly interested in the topics being discussed and found them to be relevant to their lives.

Slightly modifying a classroom assessment technique known as the "Minute Paper" (Angelo and Cross, 1993), at the conclusion of the lecture the students were asked to tear off a slip of paper and respond to two questions: "What did you learn today?" and "What one question about this topic do you still have?"

Students reacted eagerly to this opportunity to ask follow-up questions in a non-threatening manner which did not test their English ability nor require them to ask their questions before such a large group of their peers. The original intention was to spend a few minutes on the following day responding to the students' questions. However, the in depth nature of their queries and the concern the students expressed toward the societal issues inherent in the adoption of the new technologies prompted the instructors to eliminate the next lecture and devote the entire hour to answering the students' questions. They also decided to develop and distribute a survey instrument which would give a more complete picture of the students' experiences with and concerns about the proliferation of global communications.

\section{What students wanted to know}

The students' questions can be organised into two major categories: technicalities regarding how the systems work and concerns about some of the underlying societal issues. Their technical questions included queries about how to use communication software such as telnet, gopher, 
and Netscape; how discussion groups are conducted and managed; how to create home pages; how to "get online" and what it costs; the structuring of hypertext and hypermedia documents; and mundane items such as "What makes the server go down?"

While there were some questions regarding security ("How does the Internet provide its users with security?", "Can plagiarism happen on the Internet?"), credibility of information found on the Net, educational uses of hypermedia, and whether the long-term impact of the Internet will be good or bad for society; their primary concerns were about censorship.

Indeed, of the 30 issues-related questions submitted, 15 dealt specifically with censorship. Students seemed to have difficulty grasping the idea that no one person or single body controls the Internet. They asked:

"Who censors the information?"

"Is the Internet being watched or controlled or organised by a group of people? If yes, who are they and what do they do?"

"Will there be a special board to control the negative information on the Internet?"

"How can censorship be done? Is it possible to have it really $100 \%$ censored?"

Only one student's submission could definitely be interpreted as having concern for the potential loss of free speech. This student wrote:

I got involved in a discussion group and I see that there's no freedom of speech on the Internet, because my posted message is withdrawn from the discussion group two minutes after I posted it!!! Is [sic] free speech on the Internet exist?

Far more often students were worried about the accessibility of pornographic materials and the potential impact this could have on children and the morals of society. This theme was heard first in the essays they had written earlier in the semester on the importance of information technology for the attainment of Malaysia's goal of becoming a fully developed nation. The questions they asked at the conclusion of the lecture included:

"Is there any device that can prevent unhealthy materials from accessing computers?"

"Could access to pornographic information be blocked through the Internet?"

"Do you think censorship on the Net is possible? How?"

"How [can we] stop children from accessing the Internet?"

"What is the impact on children that access the Internet?" 


\section{Follow-up survey}

Fifty-six students ( $86 \%$ of the total enrolled) were in attendance at the time the survey instrument was distributed. Demographic information requested included age, gender, ethnic group. Analysis of the responses from the 54 who reported their age precisely (the two who indicated "18+" were omitted from the analysis), revealed their age to range from 17 to 41 years, with the mean age being 20 years and both the median and mode ages being 18 years.

Thirty-two $(57 \%)$ of the students were female and $24(43 \%)$ were male. The ethnic breakdown showed 35 students $(63 \%)$ were Malay, 9 students $(16 \%)$ were Chinese, and 12 students $(21 \%)$ were Indian. No students selected "other" or failed to identify their ethnic origin.

When asked where they have learned about information technology, particularly the Internet and multimedia; $89 \%$ reported from newspapers, $89 \%$ from their friends and family, $63 \%$ from television or radio, and 55\% from their other university lectures. Most of these students would have finished high school within the previous 12 months, yet only $20 \%$ of the students reported learning about these technologies in their high school curriculum.

All students had some experience with stand-alone computer applications including games, word processing, databases, and spreadsheets. Most had used electronic mail (63\%) and accessed the World Wide Web (71\%). Only forty-six percent of the students indicated they have participated in "discussion groups", but in actual fact this number might be quite higher as one of the most popular uses of the World Wide Web on campus is making friends with students from other countries via Alamak Chat [www.alamak.com].

The most common place for students to have access to the Internet was their campus facilities. Eighty-nine percent reported using their campus computer labs and 52\% reported using the campus library. Thirty-six percent reported accessing the Internet in the homes of their friends or family members. Only six students $(11 \%)$ reported having Internet access in their own home.

Two open-ended questions were asked to gain an understanding of student opinions about the proliferation of electronic communications. Most students felt the most positive things about the Internet were the increased access to information and the potential for communicating with (and making friends with) people from around the globe.

What they considered to be the biggest problems with the Internet can be categorised into the same two areas as their earlier questions: technical problems and societal issues. Five students complained about the frequency of server breakdowns, six noted that it took too long to 
download information, and two complained about an inadequate number of Internet-accessible computers on their campus. Twenty-five students (nearly half of the 56 surveyed) thought that the availability of pornography or "unsuitable content" and inadequate censorship capabilities were the biggest problems. Only two complained about the existence of censorship and eight expressed concern about a lack of privacy. Seven students were concerned about information overload and seven others about user addiction or students "wasting time" on the Internet.

As the surveys were being the distributed, the lecturers asked students to complete one last task: "Tell us a story; a story about you and the Internet." These stories provided an illuminating context for better understanding the students' experiences and opinions. They told of how learned to use the Internet, they content or services they like to access, how they stay in touch with family and made new friends via the Internet, their "gorgeous" girlfriends or "boys in love with me", the influence technology is having on their and their friends' lives, or the reasons they have not used the Internet.

\section{Discussion}

The student complaints regarding technical problems - server breakdowns, the time it takes to download information, and too few computers - can frequently be heard on any college campus. What surprised the authors was the number of students who said user addiction and the lack of control over content were the biggest problems with the Internet. (An unscientific survey of acquaintances in New Zealand did not indicate that 19-year-old students here share these opinions.)

The basis for these concerns can be found in the students' stories. Nine of the 53 stories submitted told of being addicted, or fear of getting addicted, to the Internet. Five others related personal experiences with "unsuitable content." Excerpts follow:

\section{Addiction}

I only learned to use the Internet a few weeks ago from my friends. I only access chat and hotmail. I've been through the other parts, but they're not as interesting as those two. Chat can really make you feel addicted. 18 year-old female.

Every day and night, time after time, the Internet is my life saver. I couldn't live without Internet. Every time the server is down, I'm down, too. I become miserable and totally depressed. If only I had my own Internet, I could make my life fully cheerful. 18 year old male.

I could be described as a competent and skilful net surfer, surfing amongst the big Kohuna's. Ask me a website and I'll take you there. Can't find a website, call me. I've also tasted my first addiction in life: netsurfing addiction. I spent seven hours non-stop on the net when I was at the height 
of my addiction. The only reason I stopped was because the server was down; had it not been down, I'd continue until the labs closed at $11 \mathrm{pm}$. Since then, I have managed to control myself and I only check my mail and do educational research... Everything's fine, at the moment. 18 year old male.

Internet is a part of my life today. Every single day, I have to get in touch with it. Without Internet, my life seems so boring and lags behind. Internet is my inspiration, because knowledge, entertainment, scientific technology, and new inventions could be set within seconds. 20 year-old male.

Most of my friends use e-mail and Netscape to chat. They get addicted to it and sit in front of the computer, potato couches [sic], all the time. I'm afraid that I would be like them, which is one of the reasons I'm not using the Internet. $18+$ year old female.

I have never accessed the Internet [because there are too few computers] and seeing some of my friends who are really crazy over the Internet really gets me nervous. They skip their breakfast, lunch, dinner, and stick before the computers.... I'm sure it must be great fun and it is so powerful that so many people get addicted to it. 20 year old female.

I always feel lonely. Every day, every hour, every minute, one by one my friends will go to the computer laboratories to spend their time on Internet or e-mail. I have the intention to follow them, too, but their behaviour makes me aware that I should not use it for the time being. Frankly speaking, I never use either the Internet nor the e-mail ... My most important reason is that I do not want to be addicted to it. 18 year old female.

\section{Content}

So far, the Internet has left a bad impression on me. The first time I accessed the Internet was about a year ago, in my friend's house. My group of friends straight away accessed some discussion group which was chatting about sex. It was quite a horrible experience for me as I saw how "open" people around the world communicate. Some of my friends even spent hours trying to download some "interesting" files through the Internet. 18 year old male.

I have a poor experience when I used the Internet in the last few weeks. My friend and I were chatting with other people from around the world. We chatted with many people from the US, Germany, Singapore, and others. While we were chatting, I saw the name "Naked 20" on the computer screen. We decided to chat with him... Do you know that he always talked dirty when we chatted with him? He asked us to make love through the Internet. But we were afraid to do that because it is against the using of Internet. We just got out from the Internet and stopped chatting with him. 19 year old female.

The first time I tried to join a chat group, I was quite shocked with the language used. Although some of them tried to hold a good conversation about nuclear weapons, most of them were talking about something [dirty] or poking jokes. 18 year old female. 


\section{Conclusion}

These Malaysian students do have knowledge of and experience using global communications via the Internet. They share some of the same complaints students in fully developed countries express - ie., too few campus connections, server breakdowns, and inadequate bandwidth for multimedia data transmission. Their favourite activities - making new friends and exploring romantic relationships - are typical adolescent behaviour across cultures.

However, their oft stated concerns about user addiction and the availability of pornographic material is perhaps unique to this group of young adults. While it was not within the scope of this investigation to determine the source of these students' values, their attitudes on these issues reflect those which can be seen within the larger Malaysian society. Almost daily the local newspapers feature stories about technological advancements and their government's efforts to make Malaysia an international centre for multimedia development and distribution. Yet they are also filled with editorial comments and quotations from government officials cautioning the populace about the importance of safeguarding the moral values of their society. One student's essay succinctly states these potentially conflicting views:

Malaysia should be a developed country in her own mould, that means not succumbing to the trends of the world. It is no use being very advanced in communication and information technology if Malaysians still rob and cheat ... The development of a nation depends largely on the evolution of her citizens, and not only how information-rich the nation can be. There should exist a balance between the intellectual and spiritual development of Malaysians before Vision 2020 can be considered successful. 


\section{References}

A global facilitator of information age. [Full text of speech by Prime Minister Datuk Seri Dr Mahathir Mohamad] (1996, August 2). The New Straits Times, pp.12-14.

Ahmad Sarji Abdul Hamid. (1996). Malaysia's Vision 2020: Understanding the Concept, Implications, and Challenges. Selected Speeches of Tan Sri Dato Seri Ahmad Safi Abdul Hamid, Chief Secretary to the Government, Malaysia. Selangor, Malaysia: Pelanduk Publications.

Angelo, T. A. and Cross, K. P. (1993). Classroom Assessment Techniques: A Handbook for College Teachers. San Francisco: Jossey-Bass, Inc.

Mahathir, Mohamad (1996a). [Untitled speech for the opening of the Multimedia Asia conference at the Putra World Trade Centre, Kuala Lumpur on 12 August 1996] http:/ / smpke.jpm.my:1025/multimedia.html

Mahathir, Mohamad (1996b). The Way Forward: Vision 2020. http:/ / smpke.jpm.my:1025/vision.html

Nancy Hunt, Ed.D.

Coordinator, Information Technology and Learning Lincoln University

PO Box 84

Canterbury, New Zealand.

huntnp@tui.lincoln.ac.nz

\author{
Alison Kuiper \\ Lecturer \\ Lincoln University \\ PO Box 84 \\ Canterbury, New Zealand. \\ kuiper@tui.lincoln.ac.nz
}

Please cite as: Hunt, N. and Kuiper, A. (1996). Malaysian students face the age of information technology. Australian Journal of Educational Technology, 12(2), 121-129. http:/ / www.ascilite.org.au/ajet/ajet12/hunt.html 